OPEN ACCESS

Edited by:

Hongbin Liu,

Hong Kong University of Science and

Technology, Hong Kong

Reviewed by:

Toshi Nagata,

The University of Tokyo, Japan

Hiroaki Saito,

The University of Tokyo, Japan

*Correspondence: Jan Taucher

jtaucher@geomar.de

Specialty section:

This article was submitted to Marine Biogeochemistry,

a section of the journal Frontiers in Marine Science

Received: 31 May 2017 Accepted: 09 April 2018

Published: 25 April 2018

Citation:

Stange P, Taucher J, Bach LT, Algueró-Muñiz M, Horn HG, Krebs L, Boxhammer T, Nauendorf AK and

Riebesell U (2018) Ocean Acidification-Induced Restructuring of the Plankton Food Web Can Influence the Degradation of Sinking Particles.

Front. Mar. Sci. 5:140.

doi: 10.3389/fmars.2018.00140

\section{Ocean Acidification-Induced} Restructuring of the Plankton Food Web Can Influence the Degradation of Sinking Particles

\author{
Paul Stange ${ }^{1}$, Jan Taucher ${ }^{1 *}$, Lennart T. Bach ${ }^{1}$, María Algueró-Muñiz ${ }^{2}$, Henriette G. Horn ${ }^{2}$, \\ Luana Krebs ${ }^{3}$, Tim Boxhammer ${ }^{1}$, Alice K. Nauendorf ${ }^{1}$ and Ulf Riebesell ${ }^{1}$ \\ ${ }^{1}$ GEOMAR Helmholtz Centre for Ocean Research Kiel, Kiel, Germany, ${ }^{2}$ Helmholtz Centre for Polar and Marine Research, \\ Alfred Wegener Institute, Biologische Anstalt Helgoland, Heligoland, Germany, ${ }^{3}$ Swiss Federal Institute of Technology, Zurich, \\ Switzerland
}

Ocean acidification $(\mathrm{OA})$ is expected to alter plankton community structure in the future ocean. This, in turn, could change the composition of sinking organic matter and the efficiency of the biological carbon pump. So far, most OA experiments involving entire plankton communities have been conducted in meso- to eutrophic environments. However, recent studies suggest that OA effects may be more pronounced during prolonged periods of nutrient limitation. In this study, we investigated how OA-induced changes in low-nutrient adapted plankton communities of the subtropical North Atlantic Ocean may affect particulate organic matter (POM) standing stocks, POM fluxes, and POM stoichiometry. More specifically, we compared the elemental composition of POM suspended in the water column to the corresponding sinking material collected in sediment traps. Three weeks into the experiment, we simulated a natural upwelling event by adding nutrient-rich deep-water to all mesocosms, which induced a diatom-dominated phytoplankton bloom. Our results show that POM was more efficiently retained in the water column in the highest $\mathrm{CO}_{2}$ treatment levels $(>800 \mu \mathrm{atm}$ $\mathrm{pCO}_{2}$ ) subsequent to this bloom. We further observed significantly lower $\mathrm{C}: \mathrm{N}$ and $\mathrm{C}: \mathrm{P}$ ratios in post-bloom sedimented $\mathrm{POM}$ in the highest $\mathrm{CO}_{2}$ treatments, suggesting that degradation processes were less pronounced. This trend is most likely explained by differences in micro- and mesozooplankton abundance during the bloom and postbloom phase. Overall, this study shows that OA can indirectly alter POM fluxes and stoichiometry in subtropical environments through changes in plankton community structure.

\footnotetext{
Keywords: sinking, particles, degradation, elemental stoichiometry, plankton, food-webs, ocean acidification, zooplankton
}

\section{INTRODUCTION}

The increase in anthropogenic carbon dioxide $\left(\mathrm{CO}_{2}\right)$ emissions during the last century has led to atmospheric $\mathrm{CO}_{2}$ concentrations that are unprecedented in the recent geological history (IPCC, 2014). About $25 \%$ of these emissions is taken up by the oceans each year (Le Quéré et al., 2016). While this dampens the atmospheric $\mathrm{CO}_{2}$ increase, it also results in shifts in carbonate chemistry 
and a reduction of seawater $\mathrm{pH}$, commonly referred to as ocean acidification (OA) (Wolf-Gladrow et al., 1999; Caldeira and Wickett, 2003). Estimates predict a 0.3-0.4 reduction in surface $\mathrm{pH}$ until the end of this century (Orr et al., 2005), which is expected to have significant impacts on physiological processes of marine biota (Doney et al., 2009).

Results from more than a decade of OA research have shown that responses differ substantially between marine organisms (Wittmann and Pörtner, 2013). While these studies helped in developing a principal understanding of how OA affects the physiology of single species, we are still largely lacking the understanding of how OA effects may manifest on the community level (Riebesell and Gattuso, 2015). Existing "whole community" studies show that both direct effects of OA on single species (Riebesell et al., 2017) and indirect effects through changes in plankton community structure (Hall-Spencer et al., 2008; Fabricius et al., 2011; Schulz et al., 2013; Paul et al., 2015; Bach et al., 2016; Gazeau et al., 2016) can significantly influence biogeochemical cycles in the ocean.

Mesocosm experiments with entire plankton communities allow us to investigate how $\mathrm{OA}$ induced changes in community structure may affect processes of biogeochemical cycles, e.g., the production and quality of particulate organic matter (POM). Changes in elemental stoichiometry of POM have the potential to influence the partitioning of carbon between the ocean and atmosphere, which is particularly important in the context of climate change. In an in situ mesocosm experiment in a Norwegian fjord, Riebesell et al. (2007) observed increased carbon to nitrogen (C:N) ratios in POM under elevated levels of $\mathrm{CO}_{2}$. The authors attributed these changes to an increase in carbon overconsumption in the dominant phytoplankton groups and outlined the possibility of a more efficient carbon pump under future ocean conditions once this carbon-enriched POM sinks out of the surface ocean. Using a global biogeochemical model, Oschlies et al. (2008) extrapolated these findings to the global ocean and found that the enhanced carbon export may lead to an expansion in suboxic water volume by up to $50 \%$ until the end of this century.

Recent mesocosm experiments showed that OA effects can be particularly pronounced during extended periods of low inorganic nutrient concentrations (Paul et al., 2015; Sala et al., 2015; Bach et al., 2016; Thomson et al., 2016). We therefore conducted an in situ mesocosm experiment in the eastern subtropical Atlantic Ocean off the coast of Gran Canaria (Canary Islands) - a region characterized by low concentrations of inorganic nutrients in particular during fall when the study took place (Arístegui et al., 2001). Halfway through the study we simulated an upwelling event of nutrient-rich water by adding collected deep-water to each mesocosm (see Taucher et al., 2017). Mesoscale upwelling events are naturally occurring frequently south of the Canary Islands, as this region is characterized by a distinct eddy-corridor (Sangrà et al., 2009). In this paper we address how OA induced changes in plankton community structure could influence the elemental composition and degradation of sinking POM.

\section{MATERIALS AND METHODS}

\section{Experimental Design}

From September to December 2014 we conducted a pelagic in situ mesocosm study in Gando Bay ( $\left.27^{\circ} 55^{\prime} 41^{\prime \prime} \mathrm{N}, 15^{\circ} 21^{\prime} 55^{\prime \prime} \mathrm{W}\right)$ off the coast of Gran Canaria (Canary Islands). We deployed nine "Kiel Off-Shore Mesocosms for Ocean Simulations" (KOSMOS, M1-M9), each consisting of a floatation frame and a mounted bag ( $2 \mathrm{~m}$ diameter) made of $1 \mathrm{~mm}$ thick thermoplastic polyurethane foil (Riebesell et al., 2013). Once deployed, the initially folded bags were lowered to a depth of $13 \mathrm{~m}$ and thereby filled with approximately $35 \mathrm{~m}^{3}$ of seawater. The bags were sealed at the bottom and top with a net (mesh size of $3 \mathrm{~mm}$ ) already before deployment in order to exclude unequally distributed nekton and large zooplankton (e.g., fish or jellyfish) from the experiment. The lowered bags were left open for 4 days to allow water exchange and ensure similar starting conditions in all mesocosms. Subsequently, the water bodies inside the mesocosms were enclosed by lifting the upper part of the bags above the sea surface, while divers simultaneously closed the bottom of each mesocosm with sediment traps. The collection cylinders of these traps were connected to silicon tubes, which were fixed to the floatation frames above sea surface (Boxhammer et al., 2016). Closing the mesocosms marked the start of the experiment on September 27, 4 days before the first $\mathrm{CO}_{2}$ addition.

To simulate different OA scenarios, we added different amounts of $\mathrm{CO}_{2}$-saturated seawater to the mesocosms. In order to reduce the immediate stress response, the addition was conducted gradually in 4 consecutive steps. The first addition was performed on the October 1 and marks the beginning of the experimental manipulation (day $0=\mathrm{t} 0$ ). Target concentrations were reached after the 4 th addition on October 7 . Table 1 depicts the mean $\mathrm{CO}_{2}$ concentrations in the respective mesocosms.

On October 23 (t22) approximately $85 \mathrm{~m}^{3}$ of deep-water were collected with a deep-water collecting system (described in detail by Taucher et al., 2017) from $650 \mathrm{~m}$ depth, approximately $7.5 \mathrm{~km}$ northeast of the study site. The collector was moored adjacent to the mesocosms. During the night between t23 and t24, approximately $20 \%$ of each mesocosms' volume was removed and replaced by equivalent amounts of nutrientrich deep-water. Exact mixing ratios were calculated based on previously determined mesocosm volumes and target nutrient concentrations (Taucher et al., 2017). In total, the study lasted 61 days with the last sampling on $\mathrm{t} 55$ and $\mathrm{t} 57$ for the water column and sediment trap, respectively.

Alongside the regular sampling routine, we dedicated extensive effort to continuous maintenance of each mesocosm, including cleaning of the mesocosm walls. While divers regularly cleaned the outside, a cleaning ring was used to wipe the inside of the walls every week (Riebesell et al., 2013). This procedure prohibits wall growth, except for the flange ring connecting the mesocosm to the sediment trap and the funnel of the sediment trap, which are too narrow to be cleaned with the ring. Cleaning of these parts was thus performed by divers inside the mesocosms on t56, after the last sampling of the water column. 


\section{Sampling Procedure Water Column}

Samples were taken every second day between 9 a.m. and 12 p.m. We used two sampling systems simultaneously: (1) an integrating water sampler (IWS, HYDRO-BIOS, Kiel) for parameters that are sensitive to gas exchange or contamination and require low amounts of sample volume (e.g., carbonate chemistry) and (2) a vacuum pumping system for parameters that require large amounts of sample volume (e.g., particulate matter) (Taucher et al., 2017). Both systems allowed for integrated sampling of the entire water column of each mesocosm from 0 to $13 \mathrm{~m}$ water depth. All water column parameters presented in this study are thus given as integrated values for each mesocosm on the respective sampling day. Sampling was conducted every second day except for the time directly after deep-water addition ( $\mathrm{t} 25-$ t33), where samples were taken every day. Water collected with the pumping system was stored in 20 L carboys and transferred in a temperature-controlled room (set to in situ temperature) once they were transported back to the laboratory facilities. Carboys were always carefully mixed before withdrawing subsample volume in order to avoid sinking bias.

Additionally, net hauls were conducted on nine occasions during the 61 days experiment in order to estimate the abundance of mesozooplankton (e.g., copepods, appendicularians). Sampling frequency was restricted to one net haul every 4th sampling day in order to avoid overfishing. Samples were taken using an Apstein net $(55 \mu \mathrm{m}$ mesh size, $17 \mathrm{~cm}$ diameter opening) with a sampling volume of $295 \mathrm{~L}$ per haul. The net content was transferred into $500 \mathrm{~mL}$ Kautex bottles and immediately preserved with $4 \%$ formaldehyde buffered with sodium tetraborate solution until identification.

For the determination of microzooplankton abundances, $250 \mathrm{~mL}$ of unfiltered seawater was taken from the $20 \mathrm{~L}$ carboys and filled into brown glass bottles. Samples were preserved using acidic Lugol's solution (1-2\% final concentration) and stored in the dark until enumeration with an inverse light microscope (section Zooplankton Counts).

Environmental boundary conditions [in situ temperature, salinity, $\mathrm{pH}$, dissolved oxygen, chlorophyll $a$, and photosynthetically active radiation (PAR)] were monitored inside each mesocosm and in the surrounding seawater every sampling day using a hand-held self-logging CTD probe (CTD60M, Sea and Sun Technologies).

\section{Sediment Trap}

Sedimented POM was collected from each mesocosm every $48 \mathrm{~h}$ starting at $\mathrm{t}-3$. Sampling was always carried out before the water column samples were taken to avoid re-suspension of sedimented matter. A detailed description of the sampling procedure is provided by Boxhammer et al. (2016). Briefly, sedimented material was pumped into $5 \mathrm{~L}$ Schott Duran glass bottles through the silicon tube connecting the collection cylinder of the sediment trap to the surface. All samples were collected within $0.5-1 \mathrm{~h}$ and immediately stored in large coolers filled with seawater and additional cool packs for the remaining sampling procedure to avoid warming and minimize bacterial degradation of the material. Once collection was finished, sediment trap samples were transported to the land-based facilities and processed as described in section POM in Sediment Trap Samples.

\section{Sample Analysis \\ Chlorophyll a and Phytoplankton Pigments}

Chlorophyll $a$ and phytoplankton pigment concentrations were determined using reverse-phase high-performance liquid chromatography (HPLC). For this, we filtered up to $1.5 \mathrm{~L}$ of seawater onto glass fiber filters (nominal pore size of $0.7 \mu \mathrm{m}$, $25 \mathrm{~mm}$ diameter, Whatman) by gentle vacuum filtration $(<200$ mbar). During filtration, samples were covered with aluminum foil to reduce exposure to light. Pigments were extracted in acetone $(90 \%)$ by homogenization of the filters with glass beads in a cell mill. Samples were then centrifuged $(10 \mathrm{~min}, 5,200$ $\mathrm{rpm}, 4^{\circ} \mathrm{C}$ ) and the supernatant was filtered through $0.2 \mu \mathrm{m}$ PTFE filters (VWR International). Pigment concentrations were determined in the supernatant by reverse-phase highperformance liquid chromatography (HPLC; Thermo Scientific HPLC Ultimate 3000 with an Eclipse XDB-C8 3.5 u $4.6 \times 150$ column; Van Heukelem and Thomas, 2001).

Contributions of individual phytoplankton groups to total chlorophyll $a$ were then calculated using the software CHEMTAX (Mackey et al., 1996).

\section{Zooplankton Counts}

Mesozooplankton was analyzed quantitatively and taxonomically using a stereomicroscope (Olympus SZX9). Copepod abundances include copepodites as well as adults. Microzooplankton abundances were determined following the method described by Utermöhl (1931) using an inverted microscope (Zeiss Axiovert 25). Only the dominant groups of microzooplankton were counted, i.e., ciliates and heterotrophic dinoflagellates.

\section{POM in Water Column Samples}

For the determination of total particulate carbon (TPC), as well as particulate organic carbon, nitrogen and phosphorous (POC, PON, POP), we took up to $1 \mathrm{~L}$ subsample from the $20 \mathrm{~L}$ carboys. Subsamples were filtered with a gentle vacuum ( $<200 \mathrm{mbar}$ ) onto combusted glass fiber filters (nominal pore size of $0.7 \mu \mathrm{m}$, $25 \mathrm{~mm}$ diameter, Whatman). Filters for the determination of TPC were dried at $60^{\circ} \mathrm{C}$ over night and transferred into tin cups until analysis. Filters for POC and PON analysis were stored in combusted glass petri dishes at $-20^{\circ} \mathrm{C}$, while POP filters were directly transferred into $40 \mathrm{~mL}$ glass bottles and frozen at $-20^{\circ} \mathrm{C}$. POC,PON filters were fumed with hydrochloric acid (37\%) for $2 \mathrm{~h}$ before measurement in order to remove particulate inorganic carbon (PIC). Concentrations of TPC, POC and PON were determined using an elemental $\mathrm{CN}$ analyser (EuroEA) following Sharp (1974).

POP filters were placed in $40 \mathrm{~mL}$ of deionized water with oxidizing decomposition reagent (“Oxisolve," Merck) and autoclaved for $30 \mathrm{~min}$ in a pressure cooker to oxidize the particulate organic phosphorus to orthophosphate. After cooling, POP concentrations were determined by spectrophotometric 
analysis analogous to the method for dissolved inorganic phosphate, following Hansen and Koroleff (1999).

\section{POM in Sediment Trap Samples}

Quantities of the sediment trap material suspended in the $5 \mathrm{~L}$ bottles (see section Sediment Trap) were determined gravimetrically after transport to the laboratory. Afterwards, we homogenized the suspended material in the sampling bottles by gently mixing, to take subsamples for a variety of parameters, which are not considered any further in this study. Total subsample volume was small (generally $<10 \%$ of bulk sample volume). The remaining bulk sample was transferred stepwise into $800 \mathrm{~mL}$ beakers and centrifuged therein with 5,236 $\times$ $\mathrm{g}$ for $10 \mathrm{~min}$ (6-16 KS centrifuge, SIGMA). The supernatant was then carefully decanted while the sedimented pellets were transferred into $110 \mathrm{~mL}$ centrifuge tubes. This procedure was repeated until the entire sample was centrifuged and transferred. For further compression, the $110 \mathrm{~mL}$ tubes were centrifuged a second time at 5,039 $\times \mathrm{g}$ for $10 \mathrm{~min}$ (3K12 centrifuge, SIGMA) and the suspension was decanted. The remaining pellets were immediately deep frozen at $-20^{\circ} \mathrm{C}$ and stored in small plastic screw cap cups. The centrifugation method was chosen over filtration since the latter only works with very small volumes of sedimented samples, due to the rapid clogging of the filter. A small sample volume of a rather patchy sample would then increase the error of later analyses for biogeochemical parameters. Concentrating the sample by centrifugation allows for an easier homogenization by grinding and thus reduces the error in later analyses.

The decanted supernatant was visually inspected for translucency and discarded unless there were still large amounts of organic material present in the supernatant. Between t 35 and t49 we observed strongly elevated sedimentation and sample volumes increased drastically. During this period, translucency of the supernatant decreased as a larger proportion of the suspended matter could not be concentrated by centrifugation. We therefore pipetted small subsamples of the homogenized supernatant onto glass fiber filters (nominal pore size of $0.7 \mu \mathrm{m}, 25 \mathrm{~mm}$ diameter, Whatman). All filters were deepfrozen at $-20^{\circ} \mathrm{C}$ immediately after filtration for subsequent analysis of TPC, POC, PON, and POP as described for water column samples. In some cases the particle density of the original samples was too low for centrifugation to compress the sedimented matter into transferrable pellets ( $\mathrm{t} 21-\mathrm{t} 33$ for $\mathrm{M} 2$ and t31-t33 for M8). In these cases we filtered subsamples of up to $100 \mathrm{~mL}$ for POM analysis of the entire samples as described for the supernatant at strongly elevated sedimentation.

The frozen centrifuge pellets were freeze-dried and ground to a very fine and homogenous powder as described in Boxhammer et al. (2016). This powder was then subsampled for the determination of TPC, POC, PON and POP. Duplicate subsamples of $2 \mathrm{mg}$ were taken for the determination of TPC and transferred into tin cups. Additionally, two similar subsamples were transferred into silver cups and acidified before measurement to remove the inorganic carbon fraction (acidified for $1 \mathrm{~h}$ with $1 \mathrm{M} \mathrm{HCl}$ and dried at $50^{\circ} \mathrm{C}$ over night). All four subsamples were measured using an elemental analyser (Euro EA-CN, Hekatech), which was calibrated with acetanilide $\left(\mathrm{C}_{8} \mathrm{H}_{9} \mathrm{NO}\right)$ and soil standard (Hekatech, catalog number HE33860101) prior to each measurement run. PIC was then calculated from total and organic carbon content. For the analysis of POP, subsamples of $2 \mathrm{mg}$ were transferred into $40 \mathrm{~mL}$ glass vials and analyzed similar to the water column samples, as described above. In this study, sediment trap data are presented as daily fluxes, which we calculated by dividing the sediment trap data of each sampling point (every $48 \mathrm{~h}$ ) by 2 . Furthermore, the daily fluxes were normalized for mesocosm volume. Volume determination is described in the introductory paper to this special issue by Taucher et al. (2017).

\section{Estimating Degradation of Sinking Particles Based on Stoichometry}

Preferential remineralization of nitrogen and phosphorus over carbon is commonly observed in sinking POM, which leads to increasing elemental ratios (C:N, C:P) with depth (Sambrotto et al., 1993; Thomas et al., 1999; Schneider et al., 2003). We calculated the changes in elemental ratios between POM collected in the sediment trap and POM sampled from the water column and defined this ratio as the stoichiometry-based degradation index $(S D I)$, as it gives an indication of the extent of degradation on sinking PM.

$$
\begin{aligned}
& S D I_{\mathrm{CN}}=\mathrm{C}: \mathrm{N}_{\text {sink }} / \mathrm{C}: \mathrm{N}_{\text {susp }} \\
& S D I_{\mathrm{CP}}=\mathrm{C}: \mathrm{P}_{\text {sink }} / \mathrm{C}: \mathrm{P}_{\text {susp }}
\end{aligned}
$$

Here, a value of 1 indicates identical elemental ratios of POM suspended in the water column (e.g., $\mathrm{C}: \mathrm{N}_{\text {susp }}$ ) and POM collected in the sediment trap (e.g., $\mathrm{C}: \mathrm{N}_{\text {sink }}$ ), while values $>1$ denote higher C:N ratios in the sedimented POM compared to the water column, thus indicating preferential remineralization of nitrogen.

The SDI was calculated on a daily basis and does therefore not account for the time lag between POM production and sinking of POM to the sediment traps (Stange et al., 2017). The reason for this was that the time lag could only be accurately determined during the bloom, when clear peaks in biomass production and POM flux to the sediment traps were observed. It is, however, unlikely that a time lag of approximately 10 days, as observed between the peak of POM production in the water column and the peak of POM sedimentation, is the same for the entire experiment. We thus decided to calculate the $S D I$ using the water column and sediment trap measurements of the same day. Nevertheless, calculating the SDI with a constant time lag of 10 days still resulted in similar trends and significant effects that were comparable to the ones reported in Table 3.

\section{Data Analysis and Statistical Approach}

To facilitate statistical analysis and a quantitative description of the data, we divided the dataset in three experimental phases based on the chlorophyll $a$ development. A detailed description of the determination of the experimental phases is given in section Chlorophyll $a$ and Experimental Phases. We applied linear regression analysis to determine the relationship between 
average $p \mathrm{CO}_{2}$ and average response of the variables during each phase. The model results were checked for normality and homoscedasticity. A linear regression was performed for several reasons. First of all, a non-linear analysis requires an underlying hypothesis of a non-linear relationship between predictor and response variable. Since there was no physiological reason to suspect a non-linear relationship, a linear model is more conservative and prevents the risk of overfitting. Furthermore, our analyses did not aim to identify a certain $\mathrm{pCO}_{2}$ level as a tipping point, but rather aimed to verify whether there is an overall effect. Cases where a non-linear relation may be underlying are discussed as such in the text. Unfortunately, Mesocosm 6 was irreparably damaged on $\mathrm{t} 26$ and thus excluded from the statistical analysis of phases II and III. Statistical analyses were undertaken using the software $R$, version 3.3.1 ( $R$ Core Team, 2013).

\section{RESULTS}

\section{Chlorophyll a and Experimental Phases}

The experiment started in oligotrophic conditions, with very low concentrations of inorganic nutrients (Figure S5) and chlorophyll $a$ (Figure 1A). Chlorophyll a concentration during phase I ( $\mathrm{t}-3-\mathrm{t} 24)$ averaged at approximately $0.1 \mu \mathrm{g} \mathrm{L}{ }^{-1}$. On $\mathrm{t} 24$ we added nutrient-rich deep-water to the mesocosms in order to simulate an eddy-induced upwelling event (for a detailed description of the deep-water addition see Taucher et al., 2017). The deepwater addition increased inorganic nutrient concentrations to approximately $3.15,0.17$, and $1.60 \mu \mathrm{mol} \mathrm{L}-1$ for $\mathrm{NO}_{3}^{-}+\mathrm{NO}_{2}^{-}$, $\mathrm{PO}_{4}^{3-}$, and $\mathrm{Si}(\mathrm{OH})_{4}$, respectively. This stimulated the rapid development of a phytoplankton bloom in phase II (t25-t35) with a peak in chlorophyll $a$ at t28 (Figure 1). The inorganic nutrients were quickly depleted and reached values close to detection limit between $\mathrm{t} 28$ and $\mathrm{t} 30$ (Figure S5). After the peak on $\mathrm{t} 28$ chlorophyll $a$ concentrations decreased rapidly in all mesocosms until they reached a minimum at $\mathrm{t} 35$. In the post-bloom phase (phase III, $\mathrm{t} 37-\mathrm{t} 55)$ inorganic nutrients and chlorophyll $a$ concentrations remained low, except for the two mesocosms with highest $\mathrm{CO}_{2}$, which displayed elevated chlorophyll $a$ until the end of the experiment. Experimental phases were defined differently for the POM flux to the sediment traps, as described in section Sediment Trap. We further observed a well-mixed water column regarding the in situ temperature and salinity throughout the experiment (Taucher et al., 2017).

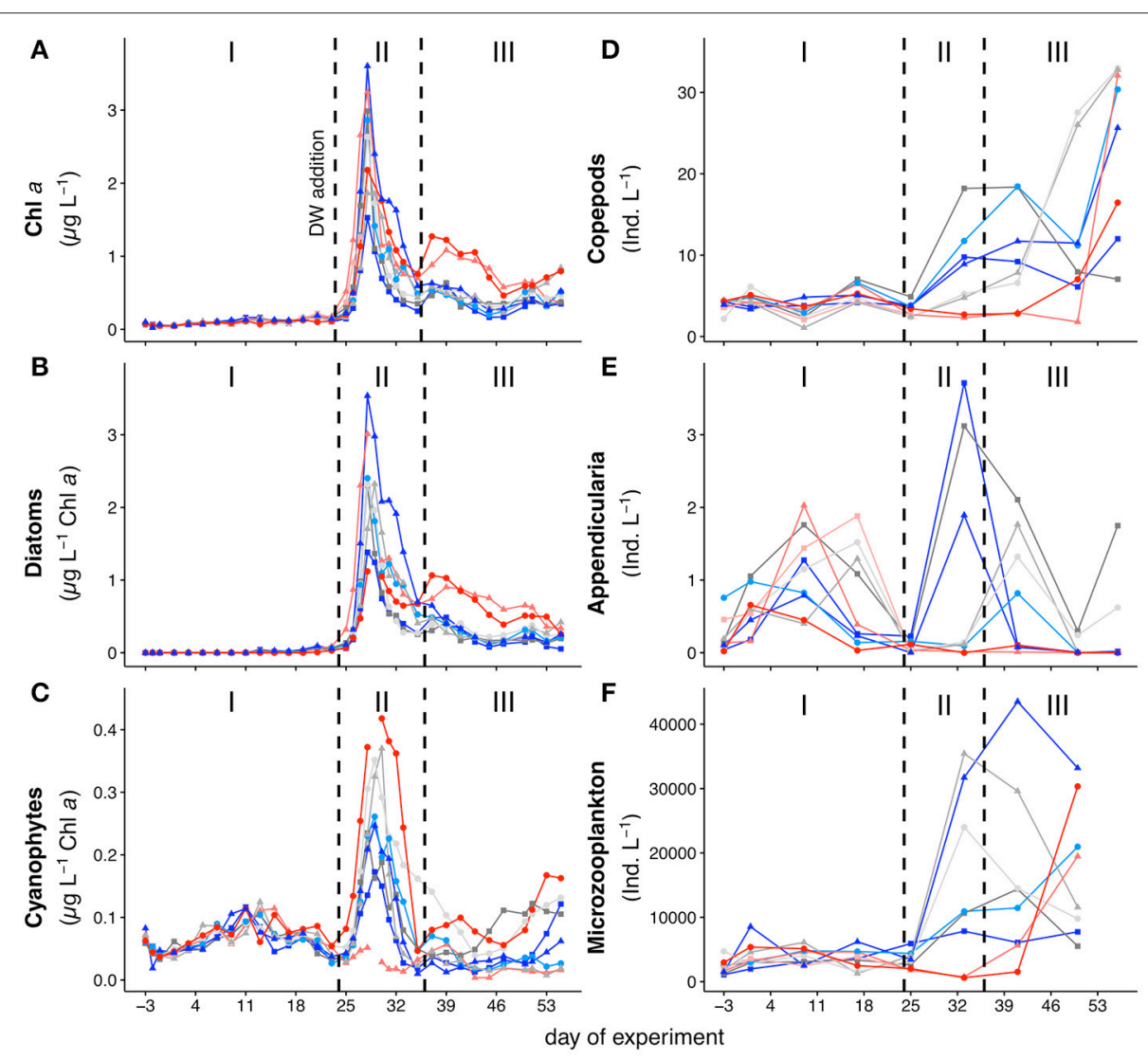

FIGURE 1 | Development of (A) chlorophyll a concentrations. (B) Abundances of diatoms, and (C) abundances of cyanophytes. (D-F) depict zooplankton abundances over the course of the experiment with (B) copepods, including both adult and all copepodite stages, (C) appendicularians, and (D) protozoan microzooplankton, mostly ciliates and heterotrophic dinoflagellates. The three different phases are indicated with I, II and III and separated by the dashed vertical lines. Note that the first dashed line also depicts the time of deep-water addition. Colors and symbols are described in Table $\mathbf{1 .}$ 
TABLE 1 | Average values for seawater $\mathrm{pCO}_{2}$ for each experimental phase, defined in section Chlorophyll a and Experimental Phases.

\begin{tabular}{|c|c|c|c|c|c|c|c|}
\hline \multirow[t]{2}{*}{ Mesocosm ID } & \multirow[t]{2}{*}{ Symbol } & \multicolumn{3}{|c|}{ Water column $\mathrm{pCO}_{2}[\mu \mathrm{atm}]$} & \multicolumn{3}{|c|}{ Sediment trap $\mathrm{pCO}_{2}[\mu \mathrm{atm}]$} \\
\hline & & $\begin{array}{l}\text { Phase I } \\
\text { (t-3-t24) }\end{array}$ & $\begin{array}{l}\text { Phase II } \\
\text { (t25-t35) }\end{array}$ & $\begin{array}{l}\text { Phase III } \\
\text { (t37-t55) }\end{array}$ & $\begin{array}{c}\text { Phase }_{\text {sed }} \text { I } \\
\text { (t-3-t33) }\end{array}$ & $\begin{array}{l}\text { Phase }_{\text {sed }} \\
\text { II (t35-t45) }\end{array}$ & $\begin{array}{l}\text { Phase }_{\text {sed }} \\
\text { III (t47-t55) }\end{array}$ \\
\hline M1 & & 401 & 374 & 326 & 392 & 333 & 318 \\
\hline M9 & & 406 & 343 & 297 & 382 & 292 & 299 \\
\hline M5 & & 502 & 404 & 427 & 464 & 406 & 431 \\
\hline M3 & & 636 & 493 & 546 & 578 & 536 & 533 \\
\hline M7 & & 746 & 571 & 672 & 678 & 632 & 671 \\
\hline M4 & & 800 & 620 & 710 & 729 & 697 & 682 \\
\hline M6 & & 976 & - & - & 970 & - & - \\
\hline M2 & & 1050 & 748 & 830 & 930 & 807 & 802 \\
\hline M8 & & 1195 & 902 & 944 & 1080 & 940 & 897 \\
\hline
\end{tabular}

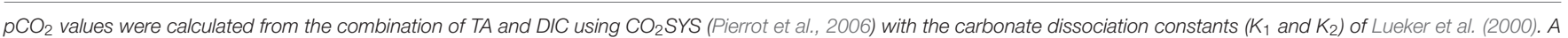
detailed description of the determination of the carbonate chemistry is given by Taucher et al. (2017).

\section{Temporal Dynamics in Plankton Community Composition}

Figures 1B,C shows the development of cyanophytes and diatoms over the course of the experiment. We only focused on these groups since they had by far the largest contribution to total chlorophyll $a$ concentrations during the respective experimental phases. During the oligotrophic phase I, (pico-)cyanobacteria (Synechococcus sp.) were the dominant phytoplankton group, with a contribution of $70-80 \%$ to total chlorophyll $a$ (Figures $\mathrm{S} 1 \mathrm{~A}, \mathrm{~B})$. Abundances of this group increased toward $\mathrm{t} 11$ and decreased afterwards until the deep-water addition on $t 24$. We observed a significant positive effect of $p \mathrm{CO}_{2}$ on the abundance of cyanophytes during phase I ( $p=0.002, F=26.67)$.

Following the deep-water addition on $\mathrm{t} 24$, the phytoplankton community underwent significant changes. Throughout phases II and III, large chain-forming diatoms, such as Leptocylindrus sp., Guinardia sp., and Bacteriastrum sp. dominated the phytoplankton community with a contribution to total chlorophyll a concentrations of $50-70 \%$ (Figure S1B). While their overall abundance decreased toward the end of the experiment, diatoms were still the dominant phytoplankton group throughout phase III. This dominance was particularly pronounced in both high $\mathrm{CO}_{2}$ mesocosms (M2 and M8, see Figure 1B) and we observed a significant positive effect of $p \mathrm{CO}_{2}$ on the abundance of diatoms during phase III $(p=0.026, F=$ 8.71 ). Plankton community structure and species succession during this study closely resembled those during natural bloom events in the Canary Islands region (Basterretxea and Arístegui, 2000; Arístegui et al., 2004) and are thus representative for natural marine ecosystems of the study area.

Figures 1B-D shows the temporal development of microand mesozooplankton abundances in all mesocosms. For the purpose of this study, we only differentiated between copepods, appendicularians and microzooplankton. Abundances of copepods were constantly low throughout phase I of the experiment. Appendicularian abundances increased during phase $\mathrm{I}$ in all mesocosms, but declined again and reached a minimum right after deep-water addition. Phase II and III were characterized by higher abundances of both groups in all mesocosms, except in M2 and M8. While abundances of appendicularians in those two mesocosms remained low until the end of the experiment, copepod abundances increased from t50 to the last sampling day. Microzooplankton abundances were overall low during phase I of the experiment and started to increase in all mesocosms after $\mathrm{t} 25$, but remained comparably low in M2 and M8.

\section{Temporal Dynamics of POM Water Column}

The temporal development of POC, PON, and POP in the water column is shown in Figures 2A-C. Water column POC and PON concentrations were only determined from $\mathrm{t} 9$ onwards as we did not have sufficient filtration volume during the first couple of days. Concentrations of all three parameters remained low from t9 onwards, but increased slightly toward the end of phase I (t17t23). With the addition of deep-water at t24, POM increased rapidly in the water column and peaked between $\mathrm{t} 30$ and $\mathrm{t} 31$ in all mesocosms. After the peak in phase II, most POM was retained in the water column and only slowly decreased during phase III. We observed a slight but significant negative effect of $p \mathrm{CO}_{2}$ on POP during phase I (Table 2), but this effect vanished during the subsequent phases. During phase III, concentrations of water column POC, PON and POP were elevated in the two highest $\mathrm{CO}_{2}$ mesocosms (M2 and M8), but we did not detect an overall significant effect of $p \mathrm{CO}_{2}$.

\section{Sediment Trap}

Peaks in POM sedimentation were temporally delayed to POM concentration peaks in the water column. This temporal delay can be explained by particle aggregation dynamics, as the rapid growth rate of phytoplankton due to the pulsed nutrient addition first resulted in an increasing abundance of smaller particles. The POM formed in the water column thus only started to sink after larger aggregates had formed several days 


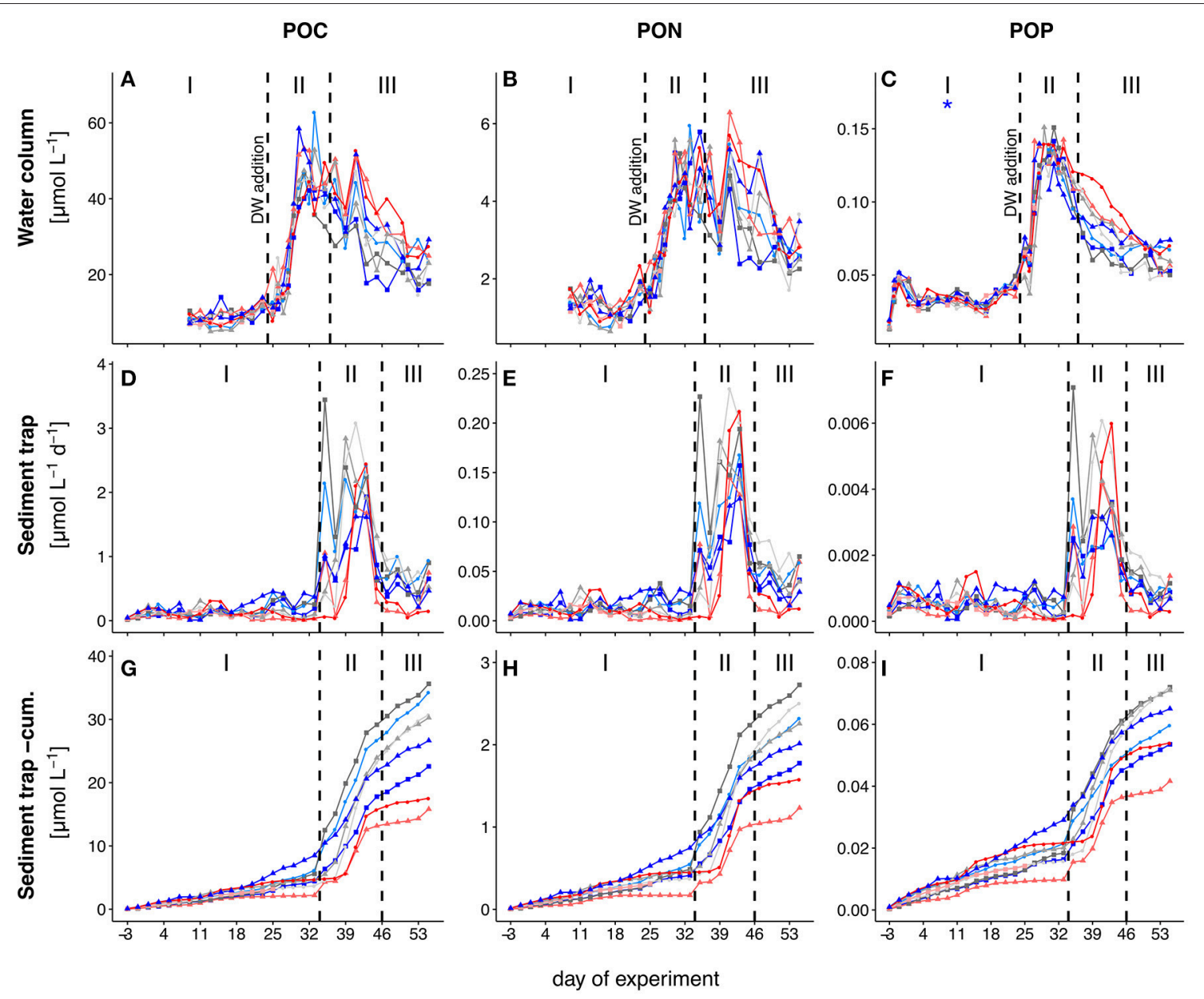

FIGURE 2 | Temporal development of standing stocks and fluxes of total particulate carbon (TPC; A,D,G), nitrogen (TPN; B,E,H) and phosphorus (TPP; C,F ,I). (A-C) and (D-F) depict POM concentrations from the water column and daily flux to the sediment trap, respectively. (G-I) show the cumulative flux of POM to the sediment trap. Colored lines depict the different mesocosms. The three different phases are indicated with I, II, and III and separated by the dashed vertical lines. Note that the first dashed line in $\mathbf{( A - C )}$ also depicts the time of deep-water addition. Colors and symbols are described in Table 1. The * denotes a statistically significant postitive (red) or negative (blue) effect of $\mathrm{CO}_{2}$ during the respective experimental phase.

after the peak in the water column (Taucher et al., in review). Due to this delay, and in order to correctly compare water column and sedimented POM, we define experimental phases differently for the sediment trap material ( phase $_{\text {sed }} \mathrm{I}=\mathrm{t}-3-$ t33; phase sed $_{\text {II }}=\mathrm{t} 35-\mathrm{t} 45$; phase $_{\text {sed }}$ III $\left.=\mathrm{t} 47-\mathrm{t} 55\right)$. While this approach does not take into account the influence of changes in sinking velocity of sedimenting particles on the time lag between OM production in the water column and its sedimentation to the sediment trap, we argue that in this experiment differences in aggregation dynamics were the main driver of this delay.

Total POM fluxes to the sediment trap were low throughout

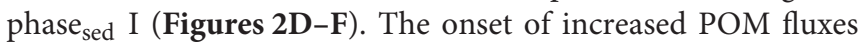
to the sediment trap followed water column POM build-up with a temporal delay of approximately 10 days. After an initial

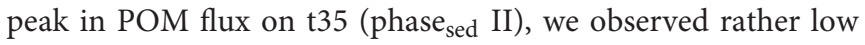
sedimentation rates on $\mathrm{t} 37$. This changed again on $\mathrm{t} 39$, after which sedimentation rates stayed high until t43. M3 and M5 had the largest contribution to the initial peak on $\mathrm{t35}$, while the remaining mesocosms showed highest sedimentation rates on $\mathrm{t} 39$ and $\mathrm{t} 43$. Rates decreased during the last phase $\mathrm{sed}_{\text {( }} 45$ to t55) but were still higher than in phase sed $\mathrm{I}$. The two mesocosms with highest $\mathrm{CO}_{2}$ concentrations (M2, M8) showed particularly low sedimentation rates during phase ${ }_{\text {sed }}$ III. However, we did not detect a significant effect of $p \mathrm{CO}_{2}$ in the regression analysis (Table 2).

The analysis of filters taken due to low translucency of the supernatant during the period of high sedimentation (t35t49; described in section POM in Sediment Trap Samples) contributed generally less than $4 \%$ to the total concentration of the respective parameter and was thus neglected. The cleaning of the lowest segment of the mesocosms and sediment trap walls on the last day of the experiment (day 57) resulted in strongly elevated sedimentation rates since there was considerable growth of benthic autotrophs on this segment (Figure S2). We thus excluded this day from the analysis. 
TABLE 2 | Statistical results from the linear regression analysis on response means over the respective phases.

\begin{tabular}{|c|c|c|c|c|c|c|c|}
\hline & \multirow[t]{2}{*}{ Phase } & \multicolumn{3}{|c|}{ Water column } & \multicolumn{3}{|c|}{ Sediment trap } \\
\hline & & $p$ & $R^{2}$ & $F$ & $P$ & $R^{2}$ & $F$ \\
\hline \multirow[t]{3}{*}{ POC } & I & 0.943 & 0.000 & 0.006 & 0.062 & 0.414 & 4.942 \\
\hline & ॥ & 0.951 & 0.000 & 0.004 & 0.523 & 0.071 & 0.461 \\
\hline & III & 0.110 & 0.369 & 3.503 & 0.274 & 0.195 & 1.45 \\
\hline \multirow[t]{3}{*}{ PON } & I & 0.368 & 0.117 & 0.924 & 0.086 & 0.362 & 3.975 \\
\hline & $\|$ & 0.568 & 0.057 & 0.365 & 0.815 & 0.009 & 0.059 \\
\hline & III & 0.209 & 0.247 & 1.971 & 0.553 & 0.062 & 0.394 \\
\hline \multirow[t]{3}{*}{ POP } & I & $0.019(-)$ & 0.569 & 9.268 & 0.279 & 0.164 & 1.372 \\
\hline & $\|$ & 0.171 & 0.287 & 2.42 & 0.889 & 0.003 & 0.021 \\
\hline & III & 0.151 & 0.311 & 2.702 & 0.616 & 0.045 & 0.280 \\
\hline \multirow[t]{3}{*}{ C:N } & I & $0.002(-)$ & 0.759 & 22.09 & 0.605 & 0.040 & 0.293 \\
\hline & ॥ & 0.649 & 0.037 & 0.229 & 0.295 & 0.179 & 1.314 \\
\hline & III & 0.075 & 0.436 & 4.641 & $0.012(-)$ & 0.682 & 12.85 \\
\hline \multirow[t]{3}{*}{$\mathrm{N}: \mathrm{P}$} & I & 0.218 & 0.208 & 1.833 & $0.019(-)$ & 0.571 & 9.321 \\
\hline & ॥ & 0.986 & 0.000 & 0.000 & 0.135 & 0.331 & 2.975 \\
\hline & III & 0.857 & 0.006 & 0.035 & 0.287 & 0.185 & 1.362 \\
\hline \multirow[t]{3}{*}{$\mathrm{C}: \mathrm{P}$} & 1 & 0.539 & 0.056 & 0.417 & $0.006(-)$ & 0.684 & 15.12 \\
\hline & $\|$ & 0.710 & 0.025 & 0.152 & 0.154 & 0.306 & 2.666 \\
\hline & III & 0.353 & 0.145 & 1.015 & $0.037(-)$ & 0.545 & 7.186 \\
\hline
\end{tabular}

Mesocosm 6 was lost after phase I and was thus not considered in the analysis in phases II and III (df for phase I = 7, and for phases II and III =6).

Significant $p$-values $(p<0.05)$ are highlighted in bold. We indicate the trend of the effect in brackets behind the $p$-value, with (+) indicating a positive and (-) and negative trend.

\section{Dynamics in Elemental Stoichiometry Water Column}

We observed higher ratios of C:N (POC:PON), N:P (PON:POP), and C:P (POC:POP) compared to Redfield proportions $(\mathrm{C}: \mathrm{N}: \mathrm{P}=106: 16: 1)$ throughout almost the entire experiment (Figures 3A-C). The only exceptions were $\mathrm{C}: \mathrm{N}$ ratios during phase I ( $\mathrm{t} 9-\mathrm{t} 13)$ and during the phytoplankton bloom right after the addition of deep-water ( $\mathrm{t} 25-\mathrm{t} 28)$. We observed a small peak in C:N stoichiometry between $\mathrm{t} 17$ and $\mathrm{t} 19$ in all mesocosms. $\mathrm{C}: \mathrm{N}$ ratios subsequently declined until the deep-water addition and fluctuated close to Redfield proportions of approximately 6-7 from t25-t28. C:N ratios increased profoundly directly after the bloom peak and nutrient depletion (t29 until t32). After this transient peak, C:N decreased toward the end of the experiment. Statistical analysis of C:N ratios averaged over the entire experiment did not reveal a significant effect of $p \mathrm{CO}_{2}$. However, when we tested each phase individually, we observed a significantly negative effect of $p \mathrm{CO}_{2}$ on C:N during phase I (see Table 2). We also found a borderline insignificant positive effect on C:N during phase III. However, the lack of significance was likely due to the effect being exclusively driven by both high $\mathrm{CO}_{2}$ mesocosms instead of a linear relationship (see Figure S3C).

Both N:P and C:P did not show a clear change during phase I. Similar to C:N, we observed minimum values for both ratios right after deep-water addition. While C:P also increased rapidly after t28 and stayed constant afterwards, N:P was characterized by a comparably slow and steady increase toward the end of the experiment. We neither observed significant treatment effects on $\mathrm{C}: \mathrm{P}$ and $\mathrm{N}: \mathrm{P}$ when averaged over the entire time, nor for any of the three phases individually.

\section{Sediment Trap}

C:N and C:P ratios of sediment trap material were above Redfield and also higher than in water column POM (Figures 3D,F). This difference was less pronounced in the N:P ratios (Figure 3E). We observed a slow and steady increase in all ratios over the course of the experiment. After t19, the variability between mesocosms increased in $\mathrm{N}: \mathrm{P}$ and $\mathrm{C}: \mathrm{P}$ and stayed high until the end of the experiment. We observed a significant negative effect of $p \mathrm{CO}_{2}$ on the C:N ratio in sedimented POM during phase sed $_{\text {III (see }}$ Table 2) as well as on N:P during phase ${ }_{s e d}$ I and C:P during phases sed I and III. These $\mathrm{CO}_{2}$ effects were driven primarily by the very low values in the two highest $\mathrm{CO}_{2}$ mesocosms ( $\mathrm{M} 2$ and M8) (Figures 3D-F).

\section{Temporal Development of the SDI}

$S D I_{\mathrm{CN}}$ was above 1 in all mesocosms throughout the experiment, with only few exceptions (see Figure 4A). This shows that C:N ratios in the sediment trap were higher compared to those in the water column for most of the time. There was no clear trend of $S D I_{\mathrm{CN}}$ over time, however, the ratio fluctuated in all mesocosms from the beginning up until t 39 and stayed more or less constant after that. We observed a significant positive treatment effect of $\mathrm{CO}_{2}$ on $S D I_{\mathrm{CN}}$ during phase I and a highly significant negative treatment effect during phase III (see Table 3).

$S D I_{\mathrm{CP}}$ did not strongly deviate from one during the majority of phase I except for the first two sampling days (Figure 4B). SDI $I_{\mathrm{CP}}$ increased during phase II and remained elevated throughout phase III except for mesocosms M4, M2 and M8. We observed significant negative $\mathrm{CO}_{2}$ treatment effects on $S D I_{\mathrm{CP}}$ during phases II and III.

\section{DISCUSSION}

\section{Temporal Development of POM Standing Stocks}

$\mathrm{CO}_{2}$-related differences in standing stocks and elemental composition of POM were detected primarily after the phytoplankton bloom in phase II and more pronounced during phase III (Figures 2, 3). In particular, we observed that in both mesocosms with highest $p \mathrm{CO}_{2}$, post-bloom water column POM remained at high concentrations longer than in low and intermediate treatment levels. This led to less sedimentation of POC, PON, and POP to the sediment trap during the study period under high $p \mathrm{CO}_{2}$ (see the cumulative plots of sedimented matter in Figures 2G-I). However, the $\mathrm{CO}_{2}$ trend was not linear, but driven almost entirely by the two mesocosms with highest $p \mathrm{CO}_{2}$ (M2 and M8, Figures S3A,B). There are three possible explanations for the observed differences in post-bloom water column POM retention: Differences in (1) particle load with ballasting minerals, such as calcite, opal or lithogenic material, (2) grazing and thus repackaging by micro- and mesozooplankton, or (3) the rate of sinking particle formation (aggregation rate). 

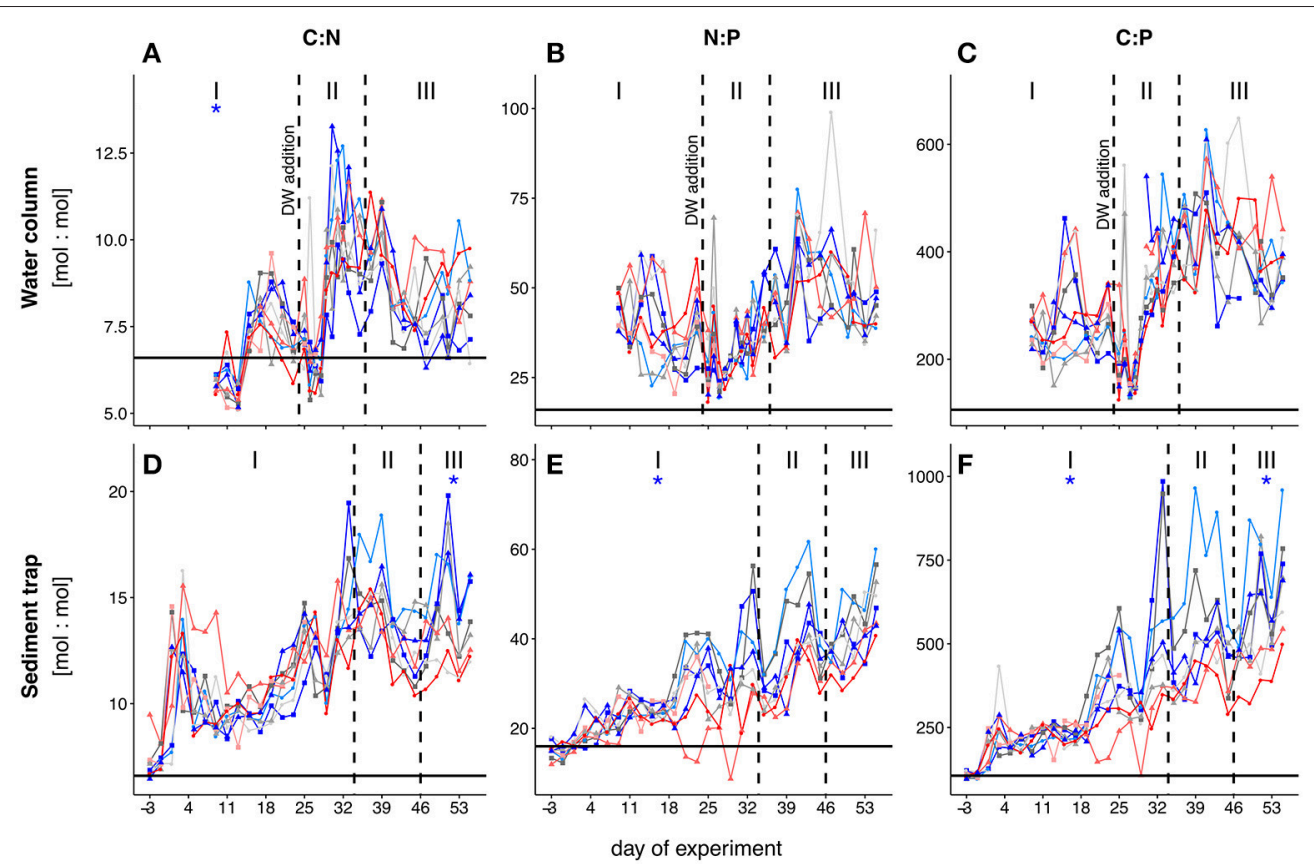

FIGURE 3 | Temporal development of POM elemental stoichiometries in the water column (A-C) and the sediment trap samples (D-F). Black horizontal lines indicate Redfield proportions for the respective elemental ratios $(C: N=6.6, N: P=16, C: P=106)$. Colored lines depict the different mesocosms. The three different phases are indicated with I, II and III and separated by the dashed vertical lines. Note that the phases for water column and sediment trap POM have been defined differently (see section Chlorophyll a and Experimental Phases). Colors and symbols are described in Table 1. The * denotes a statistically significant postitive (red) or negative (blue) effect of $\mathrm{CO}_{2}$ during the respective experimental phase.

$\mathrm{PIC} / \mathrm{POC}$ and biogenic silica (BSi)/POC ratios (Figure S4) did not give an indication for a lower ballasting effect in mesocosms M2 and M8 after the bloom and we have no reason to expect a differing supply of airborne lithogenic material to individual mesocosms. We thus conclude that the difference in POM retention was most likely driven by differences in foodweb dynamics and/or aggregation processes. Indeed, abundances of the dominant groups of mesozooplankton, i.e., copepods and appendicularians, as well as microzooplankton abundances were particularly low in both high $\mathrm{CO}_{2}$ mesocosms during phases II and III (Figures 1D-F). Although the difference in grazer abundance was mainly driven by M2 and M8, the linear regression analysis revealed significantly lower abundances of copepods on t41 with increasing $\mathrm{pCO}_{2}(F=5.469, p$ $=0.05)$. These results are further supported by the results of the multivariate analysis using Bray-Curtis dissimilarity, which showed that M2 and M8 were particularely different to the other mesocosms in terms of their plankton community composition (Taucher et al., 2017). The lower abundance of grazers in the highest $\mathrm{CO}_{2}$ treatment levels may have resulted in reduced consumption and repackaging of POM, which in turn translated into a longer residence time of phytoplankton cells and aggregates in the water column. On the other hand, the comparatively high abundances of zooplankton grazers in the other mesocosms resulted in higher clearance rates of approximately $9 \mathrm{~L} \mathrm{~d}^{-1}$ (assuming an a mean abundance of 10 ind. $\mathrm{L}^{-1}$ with an average body size of less than $500 \mu \mathrm{m}$; Kiørboe, 2011), which further illustrates the strong influence of zooplankton grazing on controlling and modifying the elemental flux to the sediment traps.

The increased retention of water column POM in M2 and M8 may also be explained by lower aggregation rates. While possibly lower turbulence inside the mesocosms compared to the surrounding water column may result in overall lower aggregation rates, the similarly mixed water columns did not suggest strong differences in turbulence between the individual mesocosms. This suggests that other processes were the key drivers of the difference in $\mathrm{OM}$ retention in the water column. Differences in phytoplankton community composition, nutritional status and growth phase of the cells can profoundly influence the coagulation efficiency (Kiørboe et al., 1990; Kiørboe and Hansen, 1993; Burd and Jackson, 2009). However, measurements of the in situ particle size spectrum by Taucher et al. (in review) did not reveal $\mathrm{CO}_{2}$ related differences for the start and rate of aggregate formation. We thus conclude that the increased retention of water column POM under elevated $\mathrm{CO}_{2}$ is primarily driven by differences in zooplankton abundance.

\section{Temporal Development of Element Stoichiometry}

Elemental ratios in water column POM were much higher than Redfield values for the majority of time during the experiment. This deviation is likely caused by very low concentrations of all major inorganic nutrients. Exceptions to this trend were observed in water column C:N ratios, which were substantially lower in the middle of phase I and right before the deep-water 

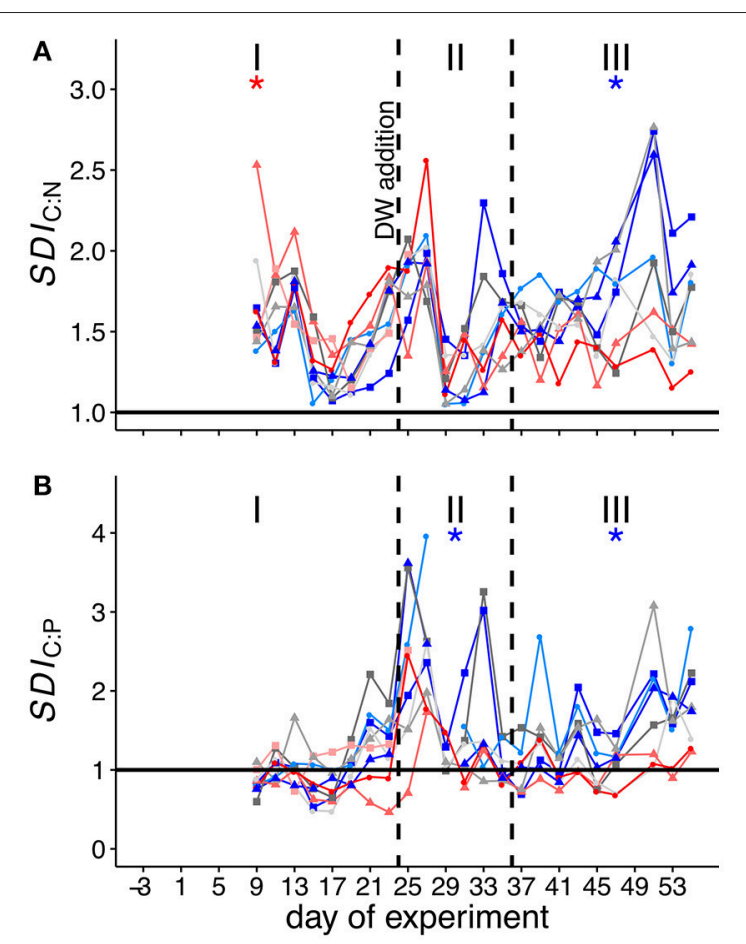

FIGURE 4 | SDI (stoichiometry-based degradation index), depicting the relation between the elemental stoichiometries of the water column and sedimented POM. SDI of C:N (A) and C:P (B). The horizontal lines indicate a $1: 1$ relationship and thus equal stoichiometries in the sediment trap and water column POM. The dashed vertical lines indicate experimental phases for water column material. Colors and symbols are described in Table 1. The * denotes a statistically significant postitive (red) or negative (blue) effect of $\mathrm{CO}_{2}$ during the respective experimental phase.

addition. We observed a small bloom of cyanophytes (mainly Synechococcus sp.) during phase I, with a peak in abundances around t11 (Figure 1C). While nutrient concentrations were generally low throughout phase I (mean concentrations of $\mathrm{NO}_{3}^{-}$ $+\mathrm{NO}_{2}^{-}=0.05 \mu \mathrm{mol} \mathrm{L}{ }^{-1}$ and $\mathrm{PO}_{4}^{3-}=0.03 \mu \mathrm{mol} \mathrm{L} \mathrm{L}^{-1}$; Figure $\mathrm{S} 5$ ), excess phosphate was available during phase I (mean $\mathrm{NO}_{3}^{-}+\mathrm{NO}_{2}^{-} / \mathrm{PO}_{4}^{3-}=2$ ). Synechococcus has been shown to have particularly low intercellular C:N ratios during exponential growth (Bertilsson et al., 2003). Since this group dominated the phytoplankton community during phase I, it is likely that their C:N signature is reflected in the C:N ratios of water column POM. The small bloom of cyanophytes collapsed after t11 and water column C:N increased correspondingly in the following days. During this period, we observed a significantly negative effect of $\mathrm{pCO}_{2}$ on water column $\mathrm{C}: \mathrm{N}$ ratios (Figure $3 \mathrm{~A}$ ). This effect again correlates well with the significantly higher abundances of cyanobacteria observed under elevated levels of $\mathrm{CO}_{2}$ during that phase.

With the addition of deep-water on $\mathrm{t} 24$, inorganic nutrient limitation was relieved for about 4 days. Consequently, C:N and $\mathrm{C}: \mathrm{P}$ ratios of water column $\mathrm{POM}$ declined immediately after the addition on $\mathrm{t} 24$ and stayed low until t28 (Figures 3A,C). C:N and $\mathrm{C}: \mathrm{P}$ increased rapidly back to elevated values as soon as inorganic nutrients from deep-water addition were depleted. This
TABLE 3 | Statistical results from the linear regression analysis on response means over the respective phases.

\begin{tabular}{|c|c|c|c|c|}
\hline & Phase & $p$ & $R^{2}$ & $\boldsymbol{F}$ \\
\hline \multirow[t]{3}{*}{$S D I_{C N}$} & 1 & $0.037(+)$ & 0.483 & 6.543 \\
\hline & $\|$ & 0.847 & 0.007 & 0.041 \\
\hline & III & $0.002(-)$ & 0.814 & 26.21 \\
\hline \multirow[t]{3}{*}{$S D I_{\mathrm{CP}}$} & I & 0.366 & 0.118 & 0.936 \\
\hline & $\|$ & $0.047(-)$ & 0.51 & 6.245 \\
\hline & III & $0.049(-)$ & 0.503 & 6.061 \\
\hline
\end{tabular}

Mesocosm 6 was lost after phase I and was thus not considered in the analysis in phases II and III (df for phase I = 7, and for phases II and III =6).

Significant $p$-values $(p<0.05)$ are highlighted in bold. We indicate the trend of the effect in brackets behind the $p$-value, with (+) indicating a positive and (-) and negative trend.

indicates carbon overconsumption, a mechanism observed in many groups of marine phytoplankton, particularly in diatoms, under nutrient-deplete conditions (Toggweiler, 1993; Riebesell et al., 2007). Indeed, diatoms were the dominant phytoplankton group during the bloom in all mesocosms, with a contribution of $>60 \%$ to the total chlorophyll $a$ concentrations (Taucher et al., 2017). Additionally, the overall low N:P ratios throughout the experiment suggests that the community was mainly phosphatelimited throughout the experiment (Figure 3B).

We observed a borderline insignificant effect $(p=0.075)$ of $p \mathrm{CO}_{2}$ on the elemental stoichiometry of water column POM during phase III of the experiment. We argue that our analysis did not reveal a significant effect as the difference in C:N wasn't linear, but solely driven by both mesocosms with highest $p \mathrm{CO}_{2}$ (Figure S3C). This difference is likely caused by differences in phytoplankton community composition. Abundances of large diatoms were significantly increased in both mesocosms with highest $p \mathrm{CO}_{2}$ during phase III (Figure 1B) and they continued to increase even after the supplied nutrients were depleted on $t 28$. The difference in abundance thus likely increased the magnitude of carbon overconsumption in the two highest $\mathrm{CO}_{2}$ treatments, resulting in slightly higher C:N ratios in M2 and M8.

\section{Influence of Community Structure on the Degradation of Sinking POM}

$S D I_{\mathrm{CN}}$ and $S D I_{\mathrm{CP}}$ were larger than 1 for the majority of the experiment. This shows that elemental ratios of sedimented POM were overall elevated compared to those of POM suspended in the water column. A similar trend has also been observed to a lesser degree in a previous study (Czerny et al., 2013), and was interpreted as an indication for preferential remineralization of both $\mathrm{N}$ and $\mathrm{P}$ relative to $\mathrm{C}$ in sinking organic material (Sambrotto et al., 1993; Thomas et al., 1999; Schneider et al., 2003).

We observed a significant positive effect of $p \mathrm{CO}_{2}$ on $S D I_{\mathrm{CN}}$ during phase $\mathrm{I}$, suggesting that degradation processes were more pronounced under high $\mathrm{CO}_{2}$ before the deep-water addition. This trend reversed during and after the bloom and a significant negative effect of $p \mathrm{CO}_{2}$ was detected for $S D I_{\mathrm{CP}}$ during phase II and $S D I_{\mathrm{CN}}$ and $S D I_{\mathrm{CP}}$ during phase III. In order to identify the mechanisms responsible for the observed differences, we evaluated the processes, which have the potential to alter C:N 
and C:P stoichiometry in sinking POM. These include the degradation of POM by grazers (protozoans and metazoans) and bacteria.

Zooplankton grazers are known to assimilate nitrogen and phosphorus more efficiently than carbon in order to maintain homeostasis, i.e., keeping their elemental composition constant (Checkley and Entzeroth, 1985; Daly et al., 1999). The excess carbon is either respired, internally stored in lipid reservoirs (e.g., in overwintering copepods in the Arctic), or defecated, resulting in fecal pellets with substantially higher C:N ratios than sinking aggregates or marine phytoplankton (Gerber and Gerber, 1979; Small et al., 1983; Daly et al., 1999). Another pathway that has the potential to impact the stoichiometry of sinking POM is bacterial degradation. It has been shown that the rapid decrease of sinking particulate matter with depth is partly associated with degradation processes by particleattached bacteria (Smith et al., 1992; Ploug and Grossart, 2000). However, production rates of free-living and particle-associated bacteria were not significantly different in the high $\mathrm{CO}_{2}$ treatments throughout the experiment (Hornick, unpublished data). Furthermore, $\mathrm{CO}_{2}$-related differences in zooplankton abundances between mesocosms only manifested during phase II and III (see Figure 1). We can therefore only speculate that the higher $S D I_{\mathrm{CN}}$ under elevated levels of $\mathrm{CO}_{2}$ during phase I is most likely related to differences in the quality of the sinking POM. Contrastingly, the significant negative effects of $p \mathrm{CO}_{2}$ on $S D I_{\mathrm{CN}}$ and $S D I_{\mathrm{CP}}$ during phase II and III are indicative for slower degradation of sinking organic material, which correlates well with the lower abundances of micro- and mesozooplankton during these periods.

In an earlier study by Riebesell et al. (2007), increased consumption of dissolved inorganic carbon (DIC) with increasing levels of seawater $p \mathrm{CO}_{2}$ was observed in an enclosed natural plankton community. The authors extrapolated these results and argued that this increased consumption may translate to enhanced carbon relative to nitrogen drawdown from the euphotic zone. In this study, we also observed slightly higher C:N ratios in water column POM in both mesocosms with highest $p \mathrm{CO}_{2}$ (Figure 3A), indicating that elevated levels of $\mathrm{CO}_{2}$ may indeed promote carbon overconsumption. However, our results show that the degradation by micro- and mesozooplankton tightly controlled the fate of POM stoichiometry with depth, with the possibility to reverse $\mathrm{CO}_{2}$ trends in elemental stoichiometry observed in the surface. We thus argue that changes in the elemental stoichiometry of suspended POM in the surface cannot be extrapolated to depth without estimating the degradation processes, which in turn are controlled by the plankton community structure.

\section{CONCLUSION}

In the present study, we show that $\mathrm{OA}$ induced changes in plankton community structure can significantly influence the degradation of sinking POM. We found that C:N ratios in suspended POM were slightly elevated after a diatom-dominated phytoplankton bloom in the two mesocosms with highest $p \mathrm{CO}_{2}$, most likely due to enhanced carbon overconsumption. Yet, POM collected in the sediment traps showed significantly lower $\mathrm{C}: \mathrm{N}$ ratios under high $\mathrm{CO}_{2}$ conditions. This indicates that degradation of sinking matter was less pronounced under elevated levels of $\mathrm{CO}_{2}$, which we mainly attribute to the lower abundances of micro- and mesozooplankton in those mesocosms during and after the phytoplankton bloom. These trends only manifested during post-bloom conditions, 4 weeks into the experiment, when differences in community structure were most pronounced. Our findings underline that $\mathrm{CO}_{2}$ induced changes in elemental stoichiometry of sinking POM are ultimately controlled by the plankton community structure. In particular, our results highlight the importance of micro- and mesozooplankton grazers on the transformation of sinking organic matter and we suggest that extrapolations of biogeochemical processes to global scales cannot be made without considering the entire planktonic food web.

\section{AUTHOR CONTRIBUTIONS}

UR, JT, LB, TB, and PS: contributed to the design of the study; LK, TB, and PS: analyzed sediment trap samples; MA-M and $\mathrm{HH}$ : analyzed the zooplankton samples; AN: analyzed the water column samples; PS interpreted the data and wrote the manuscript with comments from all co-authors.

\section{FUNDING}

This project was funded by the German Federal Ministry of Education and Research (BMBF) in the framework of the coordinated project BIOACID-Biological Impacts of Ocean Acidification, phase 2 (FKZ 03F06550). UR received additional funding from the Leibniz Award 2012 by the German Research Foundation (DFG).

\section{ACKNOWLEDGMENTS}

The authors of this paper are very thankful to the entire Gran Canaria KOSMOS consortium for their contribution to this experiment. We also would like to thank the Oceanic Platform of the Canary Islands (Plataforma Oceánica de Canarias, PLOCAN) for sharing their expertise and research facilities, and providing us with all the necessary tools to successfully conduct our research. Another special thanks goes to the Marine Science and Technology Park (Parque Científico Tecnológico Marino, PCTM) and the Spanish Bank of Algae (Banco Español de Algas, BEA), both from the University of Las Palmas (ULPGC), who provided additional facilities to run experiments, measurements, and analyses.

We are also thankful for the great support by the captain and crew of RV Hesperides for deploying and recovering the mesocosms (cruise 29HE20140924), and RV Poseidon for transporting the mesocosms and their support in testing the deep water collector during cruise POS463.

\section{SUPPLEMENTARY MATERIAL}

The Supplementary Material for this article can be found online at: https://www.frontiersin.org/articles/10.3389/fmars. 2018.00140/full\#supplementary-material 


\section{REFERENCES}

Arístegui, J., Barton, E. D., Tett, P., Montero, M. F., García-Muñoz, M., Basterretxea, G., et al. (2004). Variability in plankton community structure, metabolism, and vertical carbon fluxes along an upwelling filament (Cape Juby, NW Africa). Prog. Oceanogr. 62, 95-113. doi: 10.1016/j.pocean.2004.07.004

Arístegui, J., Hernández-León, S., Montero, M. F., and Gómez, M. (2001). The seasonal planktonic cycle in coastal waters of the Canary Islands. Sci. Mar. 65, 51-58. doi: 10.3989/scimar.2001.65s151

Bach, L. T., Taucher, J., Boxhammer, T., Ludwig, A., Achterberg, E. P., AlgueróMuñiz, M., et al. (2016). Influence of Ocean acidification on a natural winterto-summer plankton succession: first insights from a long-term mesocosm study draw attention to periods of low nutrient concentrations. PLoS ONE 11:e0159068. doi: 10.1371/journal.pone.0159068

Basterretxea, G., and Arístegui, J. (2000). Mesoscale variability in phytoplankton biomass distribution and photosynthetic parameters in the CanaryNW African coastal transition zone. Mar. Ecol. Prog. Ser. 197, 27-40. doi: 10.3354/meps197027

Bertilsson, S., Berglund, O., Karl, D. M., and Chisholm, S. W. (2003). Elemental composition of marine Prochlorococcus and Synechococcus : implications for the ecological stoichiometry of the sea. Limnol. Oceanogr. 48, 1721-1731. doi: 10.4319/lo.2003.48.5.1721

Boxhammer, T., Bach, L. T., Czerny, J., and Riebesell, U. (2016). Technical note: sampling and processing of mesocosm sediment trap material for quantitative biogeochemical analysis. Biogeosciences 13, 2849-2858. doi: 10.5194/bg-13-2849-2016

Burd, A. B., and Jackson, G. A. (2009). Particle aggregation. Ann. Rev. Mar. Sci. 1, 65-90. doi: 10.1146/annurev.marine.010908.163904

Caldeira, K., and Wickett, M. E. (2003). Oceanography: anthropogenic carbon and ocean pH. Nature 425:365. doi: 10.1038/425365a

Checkley, D. M., and Entzeroth, L. C. (1985). Elemental and isotopic fractionation of carbon and nitrogen by marine, planktonic copepods and implications to the marine nitrogen cycle. J. Plankton Res. 7, 553-568. doi: 10.1093/plankt/7.4.553

Czerny, J., Schulz, K. G., Boxhammer, T., Bellerby, R. G. J., Büdenbender, J., Engel, A., et al. (2013). Implications of elevated $\mathrm{CO}_{2}$ on pelagic carbon fluxes in an Arctic mesocosm study - an elemental mass balance approach. Biogeosciences 10, 3109-3125. doi: 10.5194/bg-10-3109-2013

Daly, K. L., Wallace, D. W. R., Smith, W. O., Skoog, A., Lara, R., Gosselin, M., et al. (1999). Non-Redfield carbon and nitrogen cycling in the Arctic: effects of ecosystem structure and dynamics. J. Geophys. Res. Ocean. 104, 3185-3199. doi: 10.1029/1998JC900071

Doney, S. C., Fabry, V. J., Feely, R. A., and Kleypas, J. A. (2009). Ocean acidification: the other $\mathrm{CO}_{2}$ problem. Ann. Rev. Mar. Sci. 1, 169-192. doi: 10.1146/annurev.marine.010908.163834

Fabricius, K. E., Langdon, C., Uthicke, S., Humphrey, C., Noonan, S., De'ath, G., et al. (2011). Losers and winners in coral reefs acclimatized to elevated carbon dioxide concentrations. Nat. Clim. Chang. 1, 165-169. doi: $10.1038 /$ nclimate 1122

Gazeau, F., Sallon, A., Maugendre, L., Louis, J., Dellisanti, W., Gaubert, M., et al. (2016). First mesocosm experiments to study the impacts of ocean acidification on plankton communities in the NW Mediterranean Sea (MedSeA project). Estuar. Coast. Shelf Sci. 138, 11-29. doi: 10.1016/j.ecss.2016.05.014

Gerber, R. P., and Gerber, M. B. (1979). Ingestion of natural particulate organic matter and subsequent assimilation, respiration and growth by tropical lagoon zooplankton. Mar. Biol. 52, 33-43. doi: 10.1007/BF00386855

Hall-Spencer, J. M., Rodolfo-Metalpa, R., Martin, S., Ransome, E., Fine, M., Turner, S. M., et al. (2008). Volcanic carbon dioxide vents show ecosystem effects of ocean acidification. Nature 454, 96-99. doi: 10.1038/nature07051

Hansen, H. P., and Koroleff, F. (1999). “Determination of nutrients," in Methods of Seawater Analysis, eds K. Grasshoff, K. Kremling, and M. Ehrhardt (Weinheim: Wiley-VCH Verlag GmbH), 159-228.

IPCC (2014). “Technical summary," in Climate Change 2013 - The Physical Science Basis, ed Intergovernmental Panel on Climate Change (Cambridge: Cambridge University Press), 31-116.

Kiørboe, T. (2011). How zooplankton feed: mechanisms, traits and trade-offs. Biol. Rev. 86, 311-339. doi: 10.1111/j.1469-185X.2010.00148.x

Kiørboe, T., and Hansen, J. L. S. (1993). Phytoplankton aggregate formation: observations of patterns and mechanisms of cell sticking and the significance of exopolymeric material. J. Plankton Res. 15, 993-1018. doi: 10.1093/plankt/15.9.993

Kiørboe, T., Andersen, K. P., and Dam, H. G. (1990). Coagulation efficiency and aggregate formation in marine phytoplankton. Mar. Biol. 107, 235-245. doi: 10.1007/BF01319822

Le Quéré, C., Andrew, R. M., Canadell, J. G., Sitch, S., Korsbakken, J. I., Peters, G. P., et al. (2016). Global Carbon Budget 2016. Earth Syst. Sci. Data 8, 605-649. doi: 10.5194/essd-8-605-2016.

Lueker, T. J., Dickson, A. G., and Keeling, C. D. (2000). Ocean $\mathrm{pCO}_{2}$ calculated from dissolved inorganic carbon, alkalinity, and equations for $\mathrm{K} 1$ and $\mathrm{K} 2$ : validation based on laboratory measurements of $\mathrm{CO}_{2}$ in gas and seawater at equilibrium. Mar. Chem. 70, 105-119. doi: 10.1016/S0304-4203(00)00022-0

Mackey, M., Mackey, D., Higgins, H., and Wright, S. (1996). CHEMTAX - a program for estimating class abundances from chemical markers:application to HPLC measurements of phytoplankton. Mar. Ecol. Prog. Ser. 144, 265-283. doi: $10.3354 /$ meps 144265

Orr, J. C., Fabry, V. J., Aumont, O., Bopp, L., Doney, S. C., Feely, R. A., et al. (2005). Anthropogenic ocean acidification over the twenty-first century and its impact on calcifying organisms. Nature 437, 681-686. doi: 10.1038/nature04095

Oschlies, A., Schulz, K. G., Riebesell, U., and Schmittner, A. (2008). Simulated 21st century's increase in oceanic suboxia by $\mathrm{CO}_{2}$-enhanced biotic carbon export. Global Biogeochem. Cycles 22:GB4008. doi: 10.1029/2007GB003147

Paul, A. J., Bach, L. T., Schulz, K. G., Boxhammer, T., Czerny, J., Achterberg, E. P., et al. (2015). Effect of elevated $\mathrm{CO}_{2}$ on organic matter pools and fluxes in a summer Baltic Sea plankton community. Biogeosciences 12, 6181-6203. doi: 10.5194/bg-12-6181-2015

Pierrot, D., Lewis, E., and Wallace, D. W. R. (2006). MS Excel Program Developed for $\mathrm{CO}_{2}$ System Calculations. ORNL/CDIAC-105a.

Ploug, H., and Grossart, H.-P. (2000). Bacterial growth and grazing on diatom aggregates: respiratory carbon turnover as a function of aggregate size and sinking velocity. Limnol. Oceanogr. 45, 1467-1475. doi: 10.4319/lo.2000.45.7.1467

R Core Team (2013). R: A Language and Environment for Statistical Computing.

Riebesell, U., and Gattuso, J. (2015). Lessons learned from ocean acidification research. Nat. Publ. Gr. 5, 12-14. doi: 10.1038/nclimate2456

Riebesell, U., Bach, L. T., Bellerby, R. G. J., Monsalve, J. R. B., Boxhammer, T., Czerny, J., et al. (2017). Competitive fitness of a predominant pelagic calcifier impaired by ocean acidification. Nat. Geosci. 10, 19-23. doi: 10.1038/ ngeo2854

Riebesell, U., Czerny, J., von Bröckel, K., Boxhammer, T., Büdenbender, J., Deckelnick, M., et al. (2013). Technical Note: a mobile sea-going mesocosm system - new opportunities for ocean change research. Biogeosciences 10, 1835-1847. doi: 10.5194/bg-10-1835-2013

Riebesell, U., Schulz, K. G., Bellerby, R. G. J., Botros, M., Fritsche, P., Meyerhöfer, M., et al. (2007). Enhanced biological carbon consumption in a high $\mathrm{CO}_{2}$ ocean. Nature 450, 545-548. doi: 10.1038/nature06267

Sala, M. M., Aparicio, F. L., Balagué, V., Boras, J. A., Borrull, E., Cardelús, C., et al. (2015). Contrasting effects of ocean acidification on the microbial food web under different trophic conditions. ICES J. Mar. Sci. J. du Cons. 73, 670-679. doi: 10.1093/icesjms/fsv130

Sambrotto, R. N., Savidge, G., Robinson, C., Boyd, P., Takahashi, T., Karl, D. M., et al. (1993). Elevated consumption of carbon relative to nitrogen in the surface ocean. Nature 363, 248-250. doi: 10.1038/363248a0

Sangrà, P., Pascual, A., Rodríguez-Santana, Á., Machín, F., Mason, E., McWilliams, J. C., et al. (2009). The canary eddy corridor: a major pathway for long-lived eddies in the subtropical North Atlantic. Deep. Res. Part I Oceanogr. Res. Pap. 56, 2100-2114. doi: 10.1016/j.dsr.2009.08.008

Schneider, B., Schlitzer, R., Fischer, G., and Nothig, E. M. (2003). Depth-dependent elemental compositions of particulate organic matter (POM) in the ocean. Glob. Biogeochem. Cycles 17:1032. doi: 10.1029/2002GB001871

Schulz, K. G., Bellerby, R. G. J., Brussaard, C. P. D., Büdenbender, J., Czerny, J., Engel, A., et al. (2013). Temporal biomass dynamics of an Arctic plankton bloom in response to increasing levels of atmospheric carbon dioxide. Biogeosciences 10, 161-180. doi: 10.5194/bg-10-161-2013

Sharp, J. H. (1974). Improved analysis for particulate organic carbon and nitrogen from seawater. Limnol. Oceanogr. 19, 984-989. doi: 10.4319/lo.1974.19.6.0984

Small, L. F., Fowler, S. W., Moore, S. A., and LaRosa, J. (1983). Dissolved and fecal pellet carbon and nitrogen release by zooplankton in tropical 
waters. Deep Sea Res. Part A. Oceanogr. Res. Pap. 30, 1199-1220. doi: 10.1016/0198-0149(83)90080-8

Smith, D. C., Simon, M., Alldredge, A. L., and Azam, F. (1992). Intense hydrolytic enzyme activity on marine aggregates and implications for rapid particle dissolution. Nature 359, 139-142. doi: 10.1038/359139a0

Stange, P., Bach, L. T., Le Moigne, F. A. C., Taucher, J., Boxhammer, T., and Riebesell, U. (2017). Quantifying the time lag between organic matter production and export in the surface ocean: implications for estimates of export efficiency. Geophys. Res. Lett. 44, 268-276. doi: 10.1002/2016GL0 70875

Taucher, J., Bach, L. T., Boxhammer, T., Achterberg, E. P., Algueró-Muñiz, M., Arístegui, J., et al. (2017). Influence of ocean acidification on oligotrophic plankton communities in the subtropical North Atlantic: an in situ mesocosm study reveals community-wide responses to elevated $\mathrm{CO}_{2}$ during a simulated deep water upwelling event. Front. Mar. Sci. 4:2800. doi: $10.3389 /$ fmars.2017.00085

Thomas, H., Ittekkot, V., Osterroht, C., and Schneider, B. (1999). Preferential recycling of nutrients-the ocean's way to increase new production and to pass nutrient limitation? Limnol. Oceanogr. 44, 1999-2004.

Thomson, P., Davidson, A., and Maher, L. (2016). Increasing $\mathrm{CO}_{2}$ changes community composition of pico- and nano-sized protists and prokaryotes at a coastal Antarctic site. Mar. Ecol. Prog. Ser. 554, 51-69. doi: 10.3354/meps11803

Toggweiler, J. R. (1993). Carbon overconsumption. Nature 363, 210-211. doi: $10.1038 / 363210 a 0$
Utermöhl, V. H. (1931). Neue wege in der quantitativen Erfassung des Planktons (mit besonderer Berücksichtigung des Ultraplanktons). Verhandlungen der Int. Vereinigung für Theor. und Angew. Limnol. 5, 567-596.

Van Heukelem, L., and Thomas, C. S. (2001). Computer-assisted high-performance liquid chromatography method development with applications to the isolation and analysis of phytoplankton pigments. J. Chromatogr. A 910, 31-49. doi: 10.1016/S.0378-4347(00)00603-4

Wittmann, A. C., and Pörtner, H.-O. (2013). Sensitivities of extant animal taxa to ocean acidification. Nat. Clim. Chang. 3, 995-1001. doi: 10.1038/nclimate1982

Wolf-Gladrow, D. A., Riebesell, U., Burkhardt, S., and Bijma, J. (1999). Direct effects of $\mathrm{CO}_{2}$ concentration on growth and isotopic composition of marine plankton. Tellus 51B, 461-476. doi: 10.3402/tellusb.v51i2.16324

Conflict of Interest Statement: The authors declare that the research was conducted in the absence of any commercial or financial relationships that could be construed as a potential conflict of interest.

Copyright (C) 2018 Stange, Taucher, Bach, Algueró-Muñiz, Horn, Krebs, Boxhammer, Nauendorf and Riebesell. This is an open-access article distributed under the terms of the Creative Commons Attribution License (CC BY). The use, distribution or reproduction in other forums is permitted, provided the original author(s) and the copyright owner are credited and that the original publication in this journal is cited, in accordance with accepted academic practice. No use, distribution or reproduction is permitted which does not comply with these terms. 